\title{
The effect of PTZ-induced epileptic seizures on hippocampal expression of PSA-NCAM in offspring born to kindled rats
}

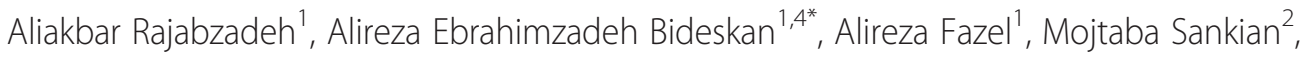 \\ Houshang Rafatpanah ${ }^{3}$ and Hossein Haghir ${ }^{1}$
}

\begin{abstract}
Background: Maternal epileptic seizures during pregnancy can affect the hippocampal neurons in the offspring. The polysialylated neural cell adhesion molecule (PSA-NCAM), which is expressed in the developing central nervous system, may play important roles in neuronal migration, synaptogenesis, and axonal outgrowth. This study was designed to assess the effects of kindling either with or without maternal seizures on hippocampal PSA-NCAM expression in rat offspring.

Methods: Forty timed-pregnant Wistar rats were divided into four groups: A) Kind ${ }^{+} / \mathrm{Seiz}^{+}$, pregnant kindled (induced two weeks prior to pregnancy) rats that received repeated intraperitoneal (i.p.) pentylenetetrazol, PTZ injections on gestational days (GD) 14-19; B) Kind ${ }^{-} / \mathrm{Seiz}^{+}$, pregnant non-kindled rats that received PTZ injections on GD14-GD19; C) Kind ${ }^{+} /$Seiz, pregnant kindled rats that did not receive any PTZ injections; and D) Kind'/Seiz', the sham controls. Following birth, the pups were sacrificed on PD1 and PD14, and PSA-NCAM expression and localization in neonates' hippocampi were analyzed by Western blots and immunohistochemistry.

Results: Our data show a significant down regulation of hippocampal PSA-NCAM expression in the offspring of $\mathrm{Kind}^{+} / \mathrm{Seiz}^{+}(p=0.001)$ and $\mathrm{Kind}^{-} / \mathrm{Seiz}^{+}(p=0.001)$ groups compared to the sham control group. The PSA-NCAM immunoreactivity was markedly decreased in all parts of the hippocampus, especially in the CA3 region, in Kind ${ }^{+} /$Seiz $^{+}(p=0.007)$ and Kind ${ }^{-} /$Seiz $^{+}(p=0.007)$ group's newborns on both PD1 and 14.

Conclusion: Our findings demonstrate that maternal seizures but not kindling influence the expression of PSA-NCAM in the offspring's hippocampi, which may be considered as a factor for learning/memory and cognitive impairments reported in children born to epileptic mothers.
\end{abstract}

Keywords: Maternal Seizure, Polysialylated Neural Cell Adhesion Molecule, Kindling, Rat Hippocampus

\section{Background}

Epilepsy is one of the most common neurological disorders $(0.5-2 \%$ of the general population). It is estimated that there are more than seven million pregnant women suffering from epilepsy in the world [1,2], and that about $1 \%$ of all pregnant women have experienced seizure during their pregnancy [3]. Although most babies born

\footnotetext{
*Correspondence: EbrahimzadehBA@mums.ac.ir

'Department of Anatomy and Cell Biology, Mashhad, Iran

${ }^{4}$ Department of Anatomy and Cell Biology, School of Medicine, Mashhad University of Medical Sciences, Azadi Sq., Vakilabad Blvd

P.O.Box 91779-48564, Mashhad, Iran

Full list of author information is available at the end of the article
}

from epileptic mother are normal, they are exposed to a higher risk of central nervous system (CNS) abnormalities $[4,5]$. Generalized seizures could lead to irreparable damages in the brain and also other organs. The two major mechanisms contributed to these damages include hypoxia and acidosis [6,7]. Several morphological changes such as neural cell shrinkage, nuclear pyknosis, and karyorrhexis in the rat pups hippocampus born from epileptic mothers having seizures during pregnancy have been reported previously [8]. A recent study has shown that maternal seizures during pregnancy cause severe cognitive disturbances and decrease in learning and memory in the offspring [9]. In addition, it seems that some of the 
learning and memory disorders in adolescence and adulthood are probably due to neurogenesis impairment, neuronal migration failure, impaired hippocampal maturation, and neurodegeneration during the embryonic period [9-11].

The majority of the cortical neurogenesis in rodents occurs during the $2^{\text {nd }}$ and $3^{\text {th }}$ week of prenatal period; and in rats, formation of the hippocampus is completed during the first 2 weeks of postnatal life $[12,13]$. It is well known that different stages of brain development are controlled by various factors such as growth factors, signaling proteins, and cell adhesion molecules; and that changes in these factors might lead to neuro-developmental impairments [14,15]. One of the molecules especially found in the CNS is the polysialylated neural cell adhesion molecule, PSANCAM [16,17]. PSA-NCAM is highly expressed in developing and migrating neurons especially during prenatal and early-postnatal neurodevelopment $[18,19]$. This molecule plays a critical role in neural plasticity, axonal outgrowth, neurogenesis, synaptogenesis; and also in several phenomena such as recognition, learning, and spatial memory [16,20,21]. Furthermore, elimination of PSA causes impairment in neural cell migration, neurite sprouting, synaptogenesis, and learning/memory [22-24].

Kindling is an experimental model for epilepsy; and pentylenetetrazol (PTZ) is a $\mathrm{GABA}_{\mathrm{A}}$ receptor antagonist commonly used as a convulsing drug in experimental studies [25]. The PTZ-induced kindling was first described by Mason and Cooper in rats (1972). This phenomenon is characterized by an increased susceptibility to seizures after repeated injections of PTZ [26].

Sato and colleagues have shown that PTZ-induced seizures increase the number of PSA-NCAM positive cells in the hippocampus of kindled rats [27]. It has been reported that kainate-induced seizures cause neuronal loss in hippocampus [28]. However, the effects of maternal seizures on PSA-NCAM expression in the hippocampus of the offspring are unknown.

Here, using western blotting and immunohistochemistry techniques, we have evaluated the effects of PTZ-induced epileptic seizures on PSA-NCAM expression and its distribution in developing rat hippocampus born to kindled and non-kindled mothers on PD1 and PD14.

\section{Methods}

This experimental research was done during 2009 in Mashhad University of Medical Sciences according to ethics committee guide lines including The National Institutes of Health(NIH) and all protocols of animal experiments have been approved by the Institution's Animal Care Committee.

\section{Animals}

Forty Wistar rats (8 week-old, weighing 180-200 g) were purchased from the animal center laboratory of Mashhad University of medical sciences, in Mashhad, Iran. The animals were maintained at the animal house under controlled conditions (12 hr light-and-dark cycles, at $21{ }^{\circ} \mathrm{C}$ with $50 \%$ relative humidity) with laboratory chow and water provided ad libitum. Before mating, the female rats were divided into two groups: Kindled and Non-Kindled ( $\mathrm{N}=20$ each).

\section{Kindling procedure}

For kindling, female rats received a single dose of $40 \mathrm{mg} / \mathrm{kg}$ PTZ (Sigma, USA) dissolved in $1 \mathrm{ml}$ of normal saline intraperitoneally (i.p.), every $48 \mathrm{hr}$. A total of 12-15 doses of PTZ were given to each rat. The convulsive behavior was observed for 20 min after each PTZ-injection. The seizures were classified according to the Racine score [29] as follows: stage 0 , no response; stage 1 , ear and facial twitching; stage 2, myoclonic jerks without upright position; stage 3 , myoclonic jerks, upright position with bilateral forelimb clonus; stage 4, tonic-clonic seizures; stage 5, generalized tonic-clonic seizures, loss of postural control. To check the maintenance of kindling state, the animals were challenged with a sub-convulsive PTZ dose $(40 \mathrm{mg} / \mathrm{kg}) 10$ days after the last kindling injection [30]. Only the rats showing generalized tonic-clonic seizures were used as kindled $\left(\mathrm{Kind}^{+}\right)$. Rats that received no PTZ before pregnancy were used as non-kindled (Kind'), and rats injected with equal volumes of normal saline (the solvent of PTZ) were used as sham controls (Kind ${ }^{-} /$Seiz $^{-}$).

\section{Breeding protocol and study groups}

Two weeks after kindling confirmation, kindled and nonkindled female rats were placed with males in the late afternoon (4-5 PM) and removed the next morning (9-10 AM). The day on which spermatozoa were found in the vaginal smear was designated as embryonic day 0 (E0). After pregnancy confirmation, rats were randomly divided into four groups as follows $(\mathrm{N}=10$ in each group): Group $\mathrm{A}$, pregnant kindled rats that received i.p. PTZ injections (40 mg/kg) during pregnancy from Gestational Days (GD) 14 to 19 every $48 \mathrm{hr}\left(\mathrm{Kind}^{+} / \mathrm{Seiz}^{+}\right)$; Group B, pregnant nonkindled rats that received i.p. PTZ injections $(40 \mathrm{mg} / \mathrm{kg}$ ) during pregnancy from GD14 to GD19 every $48 \mathrm{hr}$, exhibiting generalized tonic-clonic seizures $\left(\mathrm{Kind}^{-} / \mathrm{Seiz}^{+}\right.$); Group $\mathrm{C}$, pregnant kindled rats that did not receive any PTZ injection during pregnancy $\left(\mathrm{Kind}^{+} / \mathrm{Seiz}^{-}\right)$; and Group D, pregnant non-kindled rats injected by normal saline with equal volume of PTZ during pregnancy from GD14 to GD19 every $48 \mathrm{hr}$ (the Sham control $=\mathrm{Kind}^{-} / \mathrm{Seiz}^{-}$).

\section{Western blotting}

Following anesthesia and craniotomy, rat offspring's brain ( $\mathrm{N}=5$ for each group) were removed on PDs 1 and 14 . 
The hippocampi were isolated carefully and stored at $-80^{\circ}$ C. In the next step, $50 \mathrm{mg}$ of the hippocampus tissue from each rat was homogenized in $1 \mathrm{ml}$ of lysis buffer containing Tris- $\mathrm{HCl}$ (0.3027 gr), $\mathrm{NaCl}$ (0.4383 gr), EDTA (0.0186 gr), Triton $100 \times(0.5 \mathrm{ml})$, and a protease inhibitor cocktail (Roche, Germany). Homogenized tissues were centrifuged at $12,300 \mathrm{~g}$ for 20 minutes at $4{ }^{\circ} \mathrm{C}$. The proteins of each sample were electrophoresed under non-reducing conditions for $1 \mathrm{hr}$ at 140 constant voltages on a 10\% SDS-polyacrylamide gel. The protein mixture was then transferred from the gel onto a PVDF membrane (Millipore, Bedford, MA) using a Bio-Rad trans-blot apparatus at $300 \mathrm{~mA}$ for 15 minutes. Blots were blocked with TBS containing 5\% skim milk at $4{ }^{\circ} \mathrm{C}$ for $12 \mathrm{hr}$. After washing the blots with TBS-T, blots were incubated with anti-PSA-NCAM mouse IgM monoclonal antibody as the primary antibody (diluted 1:5000 in 5\% TBS-Skim milk) at $4{ }^{\circ} \mathrm{C}$ overnight. Following three washes with TBS-T, the blots were incubated with goat anti-mouse IgM (1:10,000 in TBS-T) as the secondary antibody for $3 \mathrm{hr}$ at room temperature. After three washing steps, the ECL substrate was applied for 3 minutes. Finally, the bands were visualized and documented with the image analyzer software KODAK 1D 3.5.2 (Syngene, UK), and quantification of the band density was determined using by normalization to the respective $\beta$-actin band density [31].

\section{Immunohistochemistry}

Rat pups ( $\mathrm{N}=5$ for each group) were anesthetized via inhalation of ether on PD1 and 14, and were perfused transcardially with $0.9 \%$ saline, followed by $4 \%$ paraformaldehyde in $0.1 \mathrm{M}$ phosphate buffer $(\mathrm{pH}=7.4)$. The brains were fixed in $1 \%$ paraformaldehyde solution $(\mathrm{pH}=7.4)$ for 2 days. After tissue processing and embedding in paraffin, $5 \mu \mathrm{m}$ coronal serial sections were prepared using a rotary microtome (Leitz 1512, Germany). The boundary of hippocampus was defined in accordance with the atlas of Paxinos and Watson [32]. Then, 10 sections including the hippocampus from each animal were chosen by uniform random sampling and mounted on poly-L-lysine coated slides. The sections were deparaffinized with the xylene, rehydrated through descending concentrations of ethanol, and rinsed with $0.1 \mathrm{M}$ phosphate buffer saline (PBS) for $10 \mathrm{~min}$. The sections were treated with EDTA $(\mathrm{pH}=8.4$ ) in PBS at $37{ }^{\circ} \mathrm{C}$ for $15 \mathrm{~min}$ to retrieve antigen and immersed in a methanol $/ \mathrm{H}_{2} \mathrm{O}_{2}$ solution (1:100) in the dark for $30 \mathrm{~min}$ to block endogenous peroxidases and rinsed 3 times, each for $5 \mathrm{~min}$, in $0.05 \mathrm{M}$ PBS plus $0.025 \%$ Trition $\mathrm{X}-100$ at room temperature. The sections were then incubated in PBS containing 10\% normal serum with 1\% BSA for 2 hours at room temperature. In order to decrease the background staining, all the sections were treated with $10 \%$ normal goat serum as the host of the antibody in PBS for $30 \mathrm{~min}$. The sections were then covered with the antiPSA-NCAM mouse IgM monoclonal antibody (diluted
1:500 in PBS with 1\% BSA) as the primary antibody in humidified chamber at $4^{\circ} \mathrm{C}$ overnight. Following the incubation period, the slides were washed extensively with PBS containing $0.025 \%$ Trition X-100 (5 min each, 3 times). After the wash, the sections were applied with HRP-conjugated secondary antibody (Goat anti-mouse IgM, Vector Laboratories, CA) diluted to 1:200 concentration in PBS with 1\% BSA at room temperature for $2 \mathrm{hr}$. All the sections were washed extensively with PBS for $3 \mathrm{~min}$ and treated with diaminobenzidine (DAB) solution (0.03gr DAB in $100 \mathrm{ml} \mathrm{PBS}$ and $200 \mu \mathrm{l} \mathrm{H}_{2} \mathrm{O}_{2}$ per $100 \mathrm{ml}$ PBS) at room temperature for $30 \mathrm{~min}$ in the dark. After washing the sections with running water, all sections were counterstained with a solution of Harris Hematoxylin for $1 \mathrm{~min}$. Finally, the sections were dehydrated in increasing graded ethanol, cleared in xylene and mounted on glass slides. The immunostaining sections were evaluated and photographed by a light microscope (Olympus DP12, Japan). In order to detect the staining intensity, all of the reactions were observed by three examiners separately. On the basis of their staining intensity, the sections were graded as very weak, +; weak, ++; moderate, +++ ; strong, ++++ [33].

\section{Statistical analysis}

The western blot data are reported as the mean \pm SEM. The statistical analysis was performed using the one-way analysis of the variance (ANOVA). Following a significant P-value $(p)$, the post hoc analysis (Tukey) was used to assess the specific group comparisons. Also the nonparametric analysis of Kruskal Wallis and Mann-Whitney tests were used to analyze the immunostaining scores. A significant difference was defined as $p<0.05$.

\section{Results}

In the present study, pregnant rats (both $\mathrm{Kind}^{+} / \mathrm{Seiz}^{+}$and $\mathrm{Kind}^{-} / \mathrm{Seiz}^{+}$groups) received three PTZ injections during GD14-19. In rats, development of hippocampus initiates from embryonic day 13 (E13), and E14-E20 is a critical period for neurogenesis and neural migration in the hippocampus [12,34,35]. Therefore, we choose GD14-19 for PTZ injections. Because hippocampal development normally continues until two weeks after birth in rat pups, we evaluated the effect of maternal epileptic seizures on PSANCAM expression in rat pups hippocampi on PDs 1 and 14.

\section{PTZ injection}

During the first few PTZ-injections, the female rats exhibited some slight symptoms consisting of short-term shaking in the head and face (stage 1 of the Racine score). However, after repeated PTZ injections (an average of 13), they exhibited tonic-colonic seizures associated with a lose of balance (stages 4 or 5 of the Racine score), (Table 1). The PTZ injection 10 days after the last kindling injection 
Table 1 Number of PTZ injections required to reach each stage of the Racine score (Mean \pm SD)

\begin{tabular}{lllllll}
\hline Seizure Score & Stage 1 & Stage 2 & Stage 3 & Stage 4 & Stage 5
\end{tabular}

\begin{tabular}{llllll}
\hline No. of PTZ injections & $2.2 \pm 0.5$ & $6.8 \pm 0.7$ & $9.8 \pm 1.1$ & $12.4 \pm 0.8$ & $13.6 \pm 1.6$
\end{tabular}

revealed that there was no significant difference in the intensity of symptoms from that observed after the last kindling injection in the same animals $(p=0.1)$.

\section{Western blotting}

After normalization against $\beta$-actin, the mean relative density of PSA-NCAM bands was calculated for all groups. As Figures 1 and 2 show, on PD1, the PSANCAM expressions of the offspring hippocampi for $\mathrm{Kind}^{+} / \mathrm{Seiz}^{+}$, Kind ${ }^{-} / \mathrm{Seiz}^{+}$, $\mathrm{Kind}^{+} / \mathrm{Seiz}^{-}$, and sham control groups were $41.07 \pm 5.1,51.34 \pm 4.09,124.61 \pm 7.12$, and $135.51 \pm 10.52$, respectively. By contrast, these values on PD14 were $25.89 \pm 2.76,32.86 \pm 3.27,50.08 \pm 5.7$, and $61.21 \pm 11.47$, respectively (Figure 2). This shows that PSA-NCAM expression significantly decreased in the hippocampi of the offspring born to mothers (both $\mathrm{Kind}^{-} / \mathrm{Seiz}^{+}$and $\mathrm{Kind}^{+} / \mathrm{Seiz}^{+}$groups) that experienced PTZ-induced seizures (stage 5 of the Racine score) during pregnancy, compared to the sham control group $(p=0.001)$. However, both on PD1 and PD14, PSANCAM expression in the hippocampus of rat pups born to $\mathrm{Kind}^{+} / \mathrm{Seiz}^{-}$and sham control groups did not show any significant differences $(p>0.05)$, (Figure 2).

\section{Immunohistochemistry}

To evaluate the effect of epileptic seizures during pregnancy on the distribution of PSA-NCAM in the hippocampus, immunohistochemistry was performed. As shown in Figure 3, on PD1, the PSA-NCAM immunoreactivity is

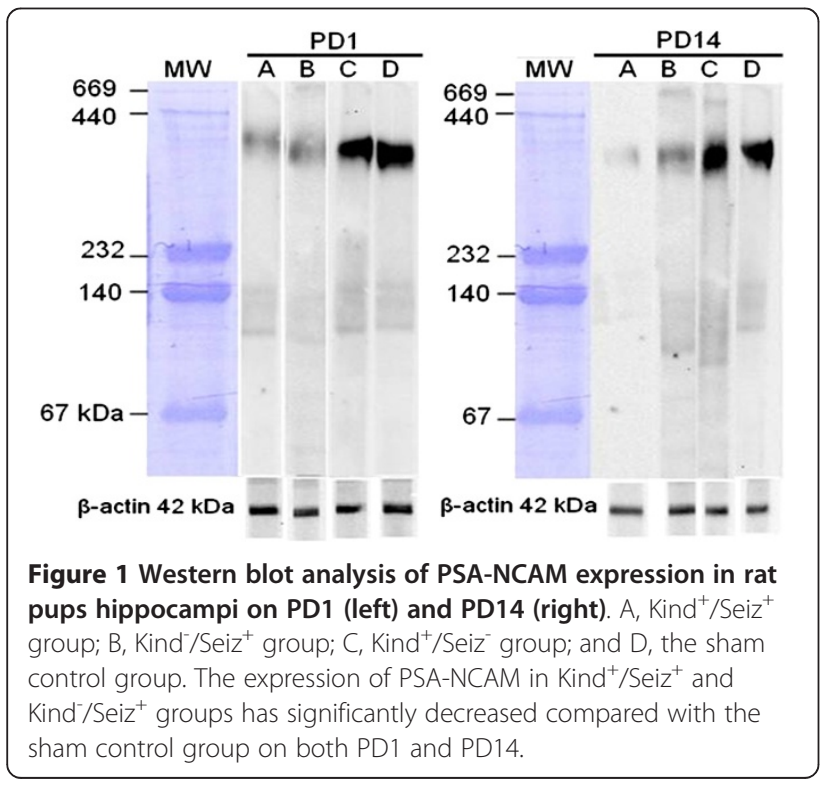

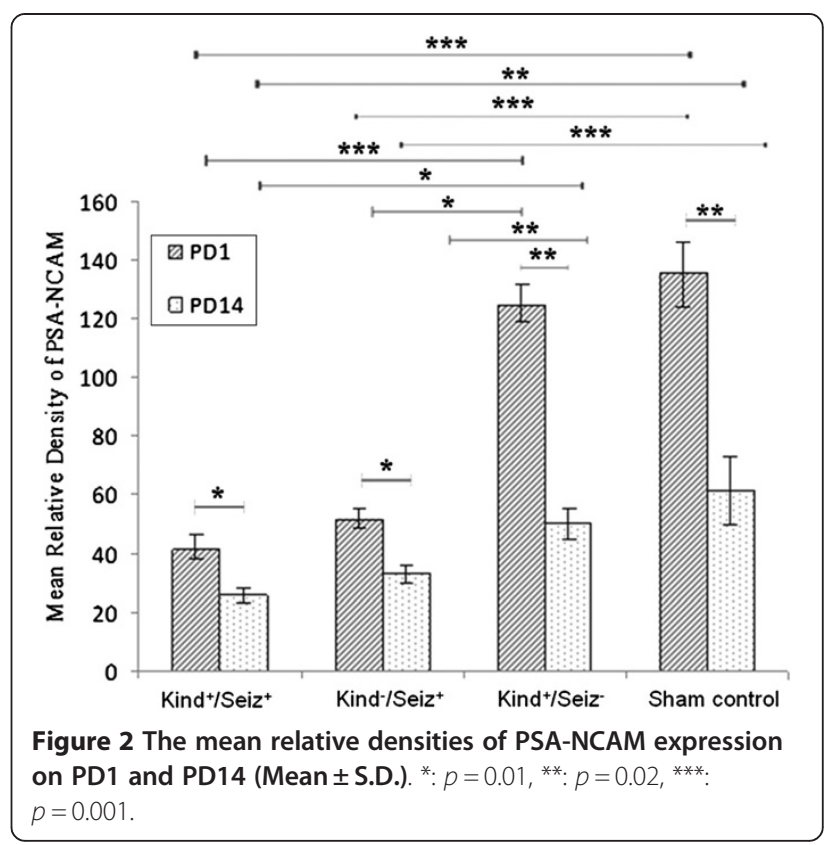

restricted to a thin layer around the nuclei of hippocampal neurons (Figure 3B). Whereas, on PD 14, the signal pattern changes to a clear cytoplasmic layer around the nuclei (Figure 3C).

On PD1, PSA-NCAM positive cells are detected in the CA1, CA3, hilus, and dentate gyrus (DG) in the hippocampi of the sham control newborn rats (Figure 4). This pattern is similar in rat offspring hippocampi of sham control and $\mathrm{Kind}^{+} / \mathrm{Seiz}^{-}$groups. By contrast, in the $\mathrm{Kind}^{-} / \mathrm{Seiz}^{+}$and $\mathrm{Kind}^{+} / \mathrm{Seiz}^{+}$groups, the PSA-NCAM immunoreactivity had more decreased in all parts of the hippocampus especially in the CA3 region $(p=0.007)$ in comparison to the sham controls (Figure 5).

The PSA-NCAM immunoreactivity was highly evident in the pyramidal cell layer of the CA1 and CA3 regions, as well as the hilus and granular layer of DG rat hippocampus born to sham control group on PD14 (Figure 6). On PD14, the PSA-NCAM immunoreactivity was reduced in all regions, with an intensive decrease in the CA3 region, of the hippocampus in the rat pups of Kind ${ }^{-} / \mathrm{Seiz}^{+}$and $\mathrm{Kind}^{+} / \mathrm{Seiz}^{+}$groups $(p=0.009)$, (Figure 7$)$. There were no significant differences observed in the PSA-NCAM immuno-staining between $\mathrm{Kind}^{-} / \mathrm{Seiz}^{+}$and $\mathrm{Kind}^{+} / \mathrm{Seiz}^{+}$ groups $(p=0.1)$, (Figure 7$)$. As shown in Figures 5 and 7 , the lowest amount of PSA-NCAM immunoreactivity was observed in the hippocampi of the pups obtained from the $\mathrm{Kind}^{+} / \mathrm{Seiz}^{+}$group.

\section{Discussion}

The effect/s of seizures on PSA-NCAM expression is a controversial issue. There have been some reports showing that epileptic seizures increase the number of PSA-NCAM positive cells in the hippocampus of kindled rats as well as 


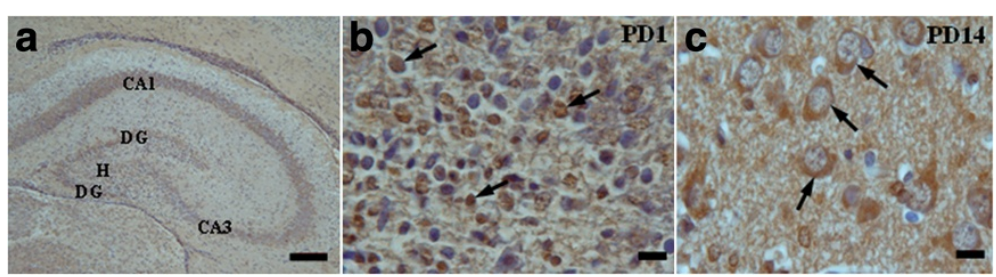

Figure 3 Coronal sections of the rat pups hippocampus: A) Different regions of sham control hippocampus; B) PSA-NCAM immunoreactivity in the hilus sub-region is restricted to the area around the nuclei in hippocampal neurons on PD1; C) a clear cytoplasmic layer around the nuclei of neurons in the hilus on PD14. Scale bars: A, $500 \mu \mathrm{m} \mathrm{B;} 50 \mu \mathrm{m}$; and C, $100 \mu \mathrm{m}$.

patients with temporal lobe epilepsy [27,36]. In contrast, other studies have reported that the number of PSANCAM positive cells severely decrease in pediatric and adult patients with temporal lobe epilepsy in comparison to the general population [37,38]. However, the authors were unable to define a reason for these discrepancies.

Although several studies have shown some effects of maternal seizures on the brain development $[7,8,11,15]$, there has been no report concerning the effects of maternal seizures on PSA-NCAM expression in the offspring. In the present study, we assessed the effects of kindling either with or without seizure induction during pregnancy on PSANCAM expression in the rat offspring hippocampus on PD1 and 14. Our observations show that PTZ-induced seizures during pregnancy severely decrease the PSANCAM expression in the developing rat hippocampus born to both kindled and non-kindled mothers.

The results of our study illustrate that PTZ-induced seizures during pregnancy decrease PSA-NCAM immunoreactivity on PD1 in the CA3 region of $\mathrm{Kind}^{+} / \mathrm{Seiz}^{+}$and $\mathrm{Kind}^{-} / \mathrm{Seiz}^{+}$hippocampus by approximately 2.8 fold. The reductions in CA1, DG, and hilus subdivisions of hippocampus were $2.5,2.5$, and 2.3 fold compared to the sham control group, respectively. Similar results were observed on PD14. The hilus of dentate gyrus is more sensitive to seizure and ischemia during postnatal life in comparison to other regions of the hippocampus [39,40]. In adult rats, epileptic seizures mainly affected CA1 and CA 3 neurons in comparison to other parts of hippocampus [28]. By contrast, the results of our study show that the CA3 region is more sensitive to maternal seizures during postnatal development. In a previous study, we have shown that maternal epileptic seizures significantly decreased the number of PSA-NCAM positive cells per unit area in the CA1, CA3, and DG subdivisions of the rat offspring hippocampus [41]. Thus, at least part of the reduction of PSA-NCAM expression detected in the western blotting experiments is likely a result of neuronal loss. However, the immunohistochemical results of our present study show a marked decrease of PSA-NCAM immunoreactivity in different subregions of the rat offspring hippocamus. Therefore, it could be concluded that the reduction of PSA-NCAM expression following PTZ-induced seizures during pregnancy is both a consequence of neuronal loss, at least in part, and a decrease of PSA-NCAM expression.

There is some evidence showing that seizures may cause aberrant neurogenesis via up-regulation of neuroblast markers such as Doublecortin (DCx), Collapsin response mediator protein-4 (CRMP-4), and PSA-NCAM, and are likely to contribute to network abnormalities in the

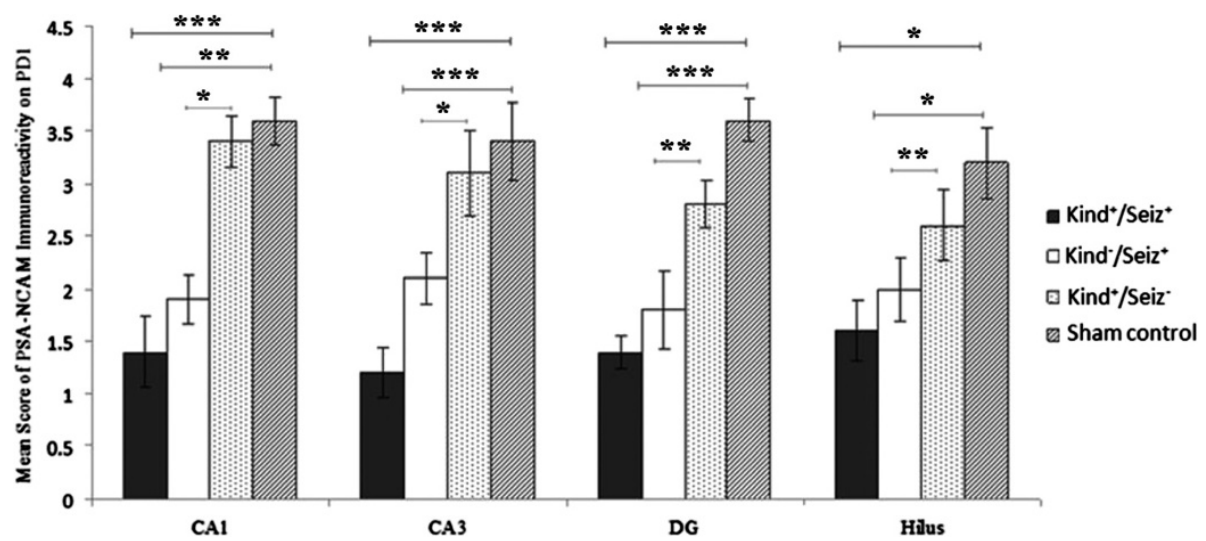

Figure 4 Mean scores of PSA-NCAM immunoreactivity in different regions of rat pups hippocampus on PD1 (Mean \pm SD). * $p=0.01,{ }^{* *}$ : $p=0.02,{ }^{* * *}: p=0.007$. 


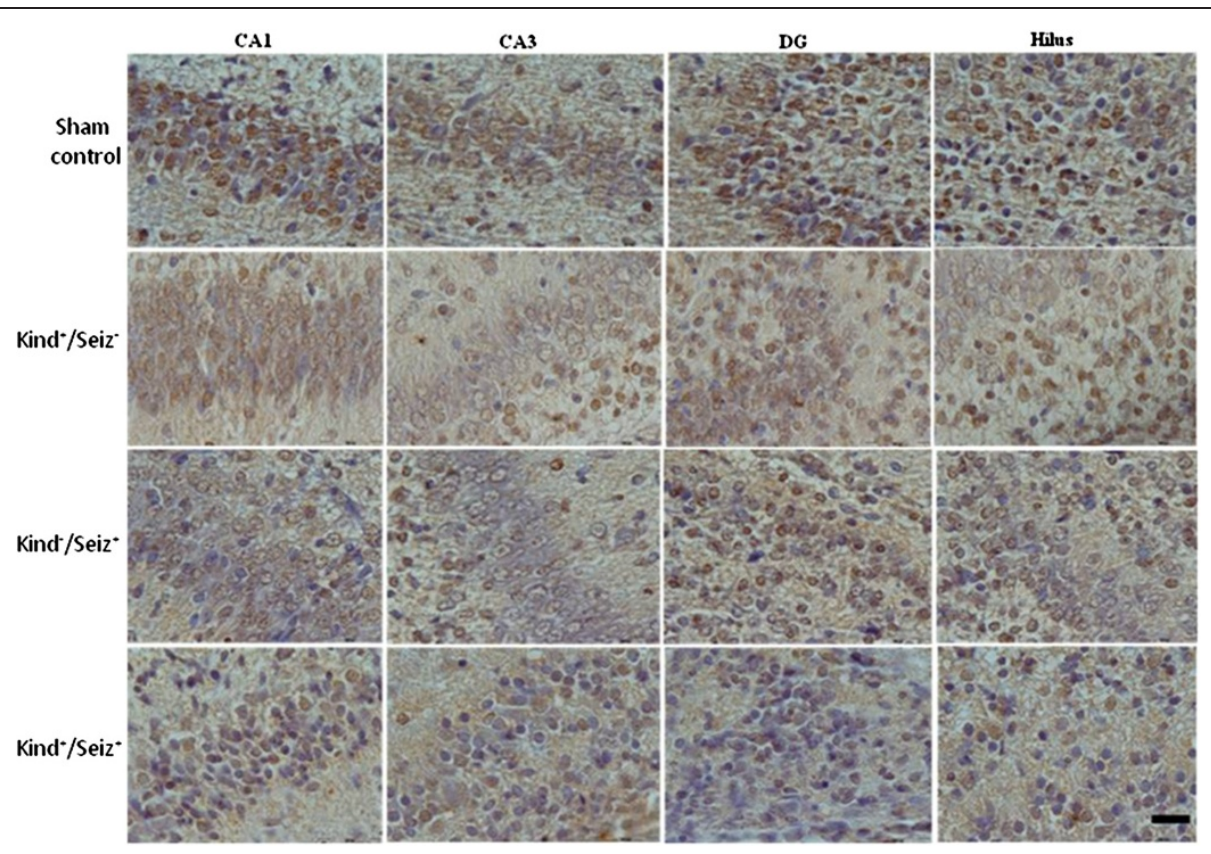

Figure 5 Immunoreactivity of PSA-NCAM in different sub regions (CA1, CA3, DG, and hilus) of rat offspring hippocampus on PD1. Scale Bar: $50 \mu \mathrm{m}$.

formation of epileptic hippocampus [42,43]. The increased PSA-NCAM expression in the hippocampal neurons and also mossy fibers following seizures could also be due to an activity-dependent mobilization in pre-existing granule cells [43]. Finally, some reports suggest that ectopic neurogenesis after seizures appears to be a maladaptive and compensatory response $[42,44,45]$. However, the reduction of PSA-NCAM expression in the rat pups hippocampus by maternal seizures is probably mediated via different mechanisms such as hypoxia, acidosis, and increasing level of stress hormones both in the mother and fetus $[7,46]$.

The reduction of PSA-NCAM expression and immunoreactivity in the hippocampus of rat pups that their mothers experienced PTZ-induced seizures during pregnancy on PD1 was similar to PD14. It can be concluded that maternal seizures probably induce decreased PSA-NCAM expression in the rat offspring hippocampus and this reduction persists until the two weeks after birth, which is a critical period in hippocampal development. Although PSANCAM expression tends to decrease in adults, a high level of PSA-NCAM expression occurs in the olfactory bulb, entorhinal cortex, hippocampus, hypothalamus, and subventricular zone in the adult brain $[17,19]$.

It has been suggested that PSA-NCAM plays a key role in the survival of immature neurons and induction of neuroplasticity, both of which are essential for learning $[47,48]$. Because migrating and maturating hippocampal neurons are PSA-NCAM-positive, a decrease in PSA-NCAM expression could be a reflection of neurogenesis impairment in the hippocampus

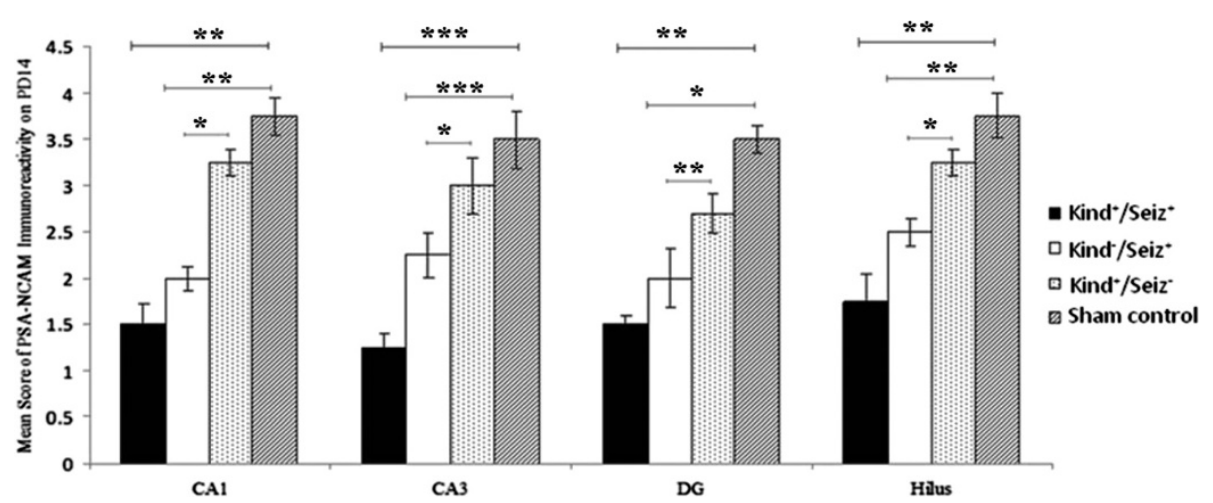

Figure 6 Mean scores of PSA-NCAM immunoreactivity in different subregions of rat pups hippocampus on PD14 (Mean \pm SD). *: $p=0.04,{ }^{* *}: p=0.02,{ }^{* * *}: p=0.009$. 


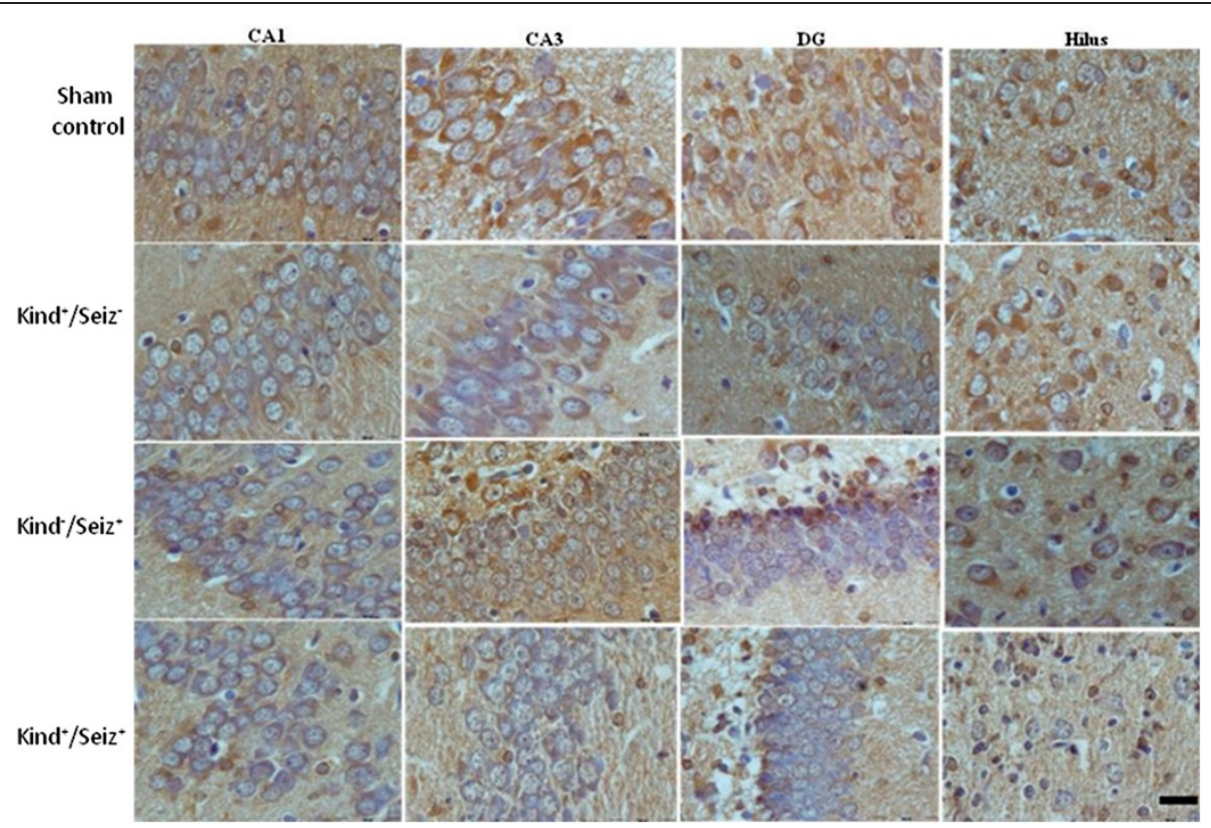

Figure 7 Immunoreactivity of PSA-NCAM in different sub regions (CA1, CA3, DG, and hilus) of rat offspring hippocampus on PD14 Scale Bar: $100 \mu \mathrm{m}$.

[48-50]. In fact, it has been reported that hippocampal activity and synaptic reorganization get impaired following reduction of PSA-NCAM expression [51]. PTZ-induced seizures during pregnancy cause intensive cognition impairment, learning/memory deficits, neurodegeneration, and also neurodevelopmental impairments in offspring during the postnatal period $[9,36]$. Indeed, it has been shown that maternal seizures could cause an imbalance between excitatory and inhibitory interneurons, as well as impaired neuronal migration in the rat offspring hippocampi, and probably induce abnormalities in the structure and function of the hippocampus $[6,15]$.

Although the exact mechanism/s of the effect of maternal seizures on fetal development is not known [11], one of the effective factors is thought to be hypoxia. Hypoxia plays an important role in fetal brain defects $[15,46,52]$. A reduction of PSA-NCAM positive cells in rat pups' hippocampus after induction of hypoxia during the prenatal period has been reported previously [53]. It is likely that hypoxic-ischemic insults in the perinatal period reduced the number of PSANCAM positive cells in the subventricular zone of the rat offspring brain [54]. In fact, hypoxia triggers a cascade of biochemical changes including high $\mathrm{Ca}^{2+}$ concentrations (mechanism of nerve cell death in response to seizure), a decrease of detoxification enzymes activities, an increase of free radicals, and an increase of arachidonic acid metabolism and activation of inflammatory-like processes in the central nervous system that could lead to an irreversible neuronal damage $[8,55]$.
Seizures during pregnancy also induce apoptosis and neurodegeneration by increasing caspase- 3 activity and decreasing $\mathrm{GABA}_{\mathrm{B} 1}$ receptors in the hippocampus of rat pups [11]. Other effective factors, such as maternal trauma during tonic-clonic seizures and elevation of adrenal hormones level, should also be taken into consideration [7]. For example, it has been shown that increasing levels of glucocorticoids adversely affect PSANCAM expression in the rat hippocampus. In addition, under normal conditions, stress hormones suppress hippocampal PSA-NCAM expression [56,57].

\section{Conclusions}

The results of our study show that epileptic seizures during pregnancy but not kindling: 1) adversely decrease PSA-NCAM expression in the rat pup's hippocampus; 2) reduce the immunoreactivity of PSA-NCAM in different regions of the hippocampus; and 3) the reduction of PSA-NCAM expression persists until two weeks after birth, a critical period in rodent's hippocampus development. The observed maternal seizure-induced hippocampal PSA-NCAM expression disturbances might be considered as a probable factor for cognitive impairments, and learning/memory defects observed in children born to epileptic mothers. It is possible that there is a relationship between maternal seizures, PSA-NCAM expression, and structural and functional alterations in offspring hippocampi. However, further studies are needed to elucidate the molecular mechanism/s involved during prenatal and postnatal periods. 


\section{Abbreviations}

CA: Corna Amunis; DAB: Diaminobenzidine; DG: Dentate Gyrus; E: Embryonic Day; GABA: Gamma-Amino Butiric Acid; GD: Gestational Day; i. p: Intraperitoneally; PBS: Phosphate Buffer Saline; PD: Postnatal Day; PSA-NCAM: Polysialylated Neural Cell Adhesion Molecule; PTZ: Pentylenetetrazol.

\section{Competing interests}

The authors declare that they have no competing interest

\section{Acknowledgement}

This study was supported financially by a grant (No. 88637) from the Deputy Research of MUMS, Mashhad, Iran. The data provided in this paper are from PhD student thesis results. In this regard, we would like to express our sincere thanks to the Vice Chancellor for research, MUMS for the financial support and we also thank Fatemeh Motejadded and Maliheh Moghaddam for their excellent technical assistance. We are also grateful to Dr. Mehrdad Pedram (Dept. of Biotechnology and Medical Genetics, Zanjan University of Medical Sciences) for his careful editing and proofreading of the manuscript and helpful comments.

\section{Author details}

${ }^{1}$ Department of Anatomy and Cell Biology, Mashhad, Iran. ${ }^{2}$ Bu-ali Research Institute, Immunology Research Center, Mashhad, Iran. ${ }^{3}$ Inflammation and inflammatory Diseases Research Center, School of Medicine, Mashhad University of Medical Sciences (MUMS), Mashhad, Iran. ${ }^{4}$ Department of Anatomy and Cell Biology, School of Medicine, Mashhad University of Medical Sciences, Azadi Sq., Vakilabad Blvd, P.O.Box 91779-48564, Mashhad, Iran

\section{Authors' contributions}

AR participated in the design of the study, and confirmation of the kindly and seizure scores. AE participated in the design of the study, helped to draft the manuscript and carried out the immunohistochemistry. AF conceived of the study, and participated in its design and coordination. MS carried out the western blotting. HR participated to manuscript revision and performed the statistical analysis. $\mathrm{HH}$ participated in the determination if hippocampus sub-regions and helped to draft the manuscript. All authors read and approved the final manuscript.

Received: 26 February 2012 Accepted: 31 May 2012

Published: 31 May 2012

\section{References}

1. Pitkanen A, Lukasiuk K: Molecular and cellular basis of epileptogenesis in symptomatic epilepsy. Epilepsy \& Behavior 2009, 14:16-25.

2. Thomas SV, Sindhu K, Ajaykumar B, Sulekha Devi PB, Sujamol J: Maternal and obstetric outcome of women with epilepsy. Seizure 2009, 18:163-6.

3. Brewer JM, Waltman PA: Epilepsy and pregnancy: maternal and fetal effects of phenytoin. Crit Care Nurse 2003, 23:93-8.

4. Chen YH, Chiou HY, Lin HC, Lin HL: Affect of seizures during gestation on pregnancy outcomes in women with epilepsy. Arch Neurol 2009, 66:979-84.

5. Battino D, Kaneko S, Andermann E, Avanzini G, Canevini MP, Canger R: Intrauterine growth in the offspring of epileptic women: a prospective multicenter study. Epilepsy Res 1999, 36:53-60.

6. Uyanikgil $Y$, Baka M, Yurtseven M, Turgut M: The effect of experimental epilepsy induced by penicillin administration during pregnancy on nestin expression in the immature rat cerebellum. A light, electron microscopic, and immunohistochemical study. Childs Nerv Syst 2004 20:176-82.

7. Lajoie J, Moshé SL: Effects of seizures and their treatment on fetal brain. Epilepsia 2004, 45:48-52.

8. Hallak M, Kupsky WJ, Hotra JW, Evans JB: Fetal rat brain damage caused by maternal seizure activity: prevention by magnesium sulfate. Am J Obstet Gynecol 1999, 181:828-834.

9. Pourmotabbed A, Nedaei SE, Cheraghi M, Moradian S, Touhidi A, Aeinfar M, Seyfi Z, Pourmotabbed T: Effect of prenatal pentylenetetrazol-induced kindling on learning and memory of male offspring. Neuroscience 2011, 172:205-11.

10. Manent JB, Jorquera I, Mazzucchelli I, Depaulis A, Perucca E, Ben-Ari Y, Represa A: Fetal exposure to GABA-acting antiepileptic drugs generates hippocampal and cortical dysplasias. Epilepsia 2007, 48:684-693.

11. Naseer MI, Shupeng L, Kim MO: Maternal epileptic seizure induced by pentylenetetrazol: apoptotic neurodegeneration and decreased $G_{A B A_{B}}$ receptor expression in prenatal rat brain. Mol Brain 2009. doi:10.1186/1756-6606-2-20.

12. Bayer SA: Development of the hippocampal region in the rat. I. Neurogenesis examined with $3 \mathrm{H}$-thymidine autoradiography. J Comp Neurol 1980, 190:87-114.

13. Porter BE: Neurogenesis and epilepsy in the developing brain. Epilepsia 2008, 49:50-54.

14. Palmini A, Najm I, Avanzini G, Babb T, Guerrini R, Foldvary-Schaefer N, Jackson G, Lüders HO, Prayson R, Spreafico R, Vinters HV: Terminology and classification of the cortical dysplasias. Neurology 2004, 62:52-8.

15. do Vale TG, da Silva AV, Lima DC, de Lima E, Torres LB, Cossa AC, de Oliveira EM, Cabral FR, Cavalheiro EA, Naffah-Mazzacoratti Mda G, Amado D: Seizures during pregnancy modify the development of hippocampal interneurons of the offspring. Epilepsy Behav 2010, 19:20-5.

16. Varea E, Nácher J, Blasco-Ibáñez JM, Gómez-Climent MA, Castillo-Gómez E, Crespo C, Martínez-Guijarro FJ: PSA-NCAM expression in the rat medial prefrontal cortex. Neuroscience 2005, 136:435-43.

17. Varea E, Castillo-Gómez E, Gómez-Climent MA, Blasco-Ibáñez JM, Crespo C, Martínez-Guijarro FJ, Nàcher J: PSA-NCAM expression in the human prefrontal cortex. J Chem Neuroanat 2007, 33:202-9.

18. Probstmeier R, Bilz A, Schneider-Schaulies J: Expression of the neural cell adhesion molecule and polysialic acid during early mouse embryogenesis. J Neurosci Res 1994, 37:324-335.

19. Bonfanti L: PSA-NCAM in mammalian structural plasticity and neurogenesis. Prog Neurobiol 2006, 80:129-64.

20. Gascon E, Vutskits L, Kiss JZ: Polysialic acid-neural cell adhesion molecule in brain plasticity: from synapses to integration of new neurons. Brain Res Rev 2007, 56:101-18.

21. Quartu M, Serra MP, Boi M, Ibba V, Melis T, Del Fiacco M: Polysialylated-neural cell adhesion molecule (PSA-NCAM) in the human trigeminal ganglion and brainstem at prenatal and adult ages. $B M C$ Neurosci 2008. doi:10.1186/1471-2202-9-108.

22. Yamamoto N, Inui K, Matsuyama Y, Harada A, Hanamura K, Murakami F, Ruthazer ES, Rutishauser U, Seki T: Inhibitory mechanism by polysialic acid for lamina-specific branch formation of thalamocortical axons. J Neurosci 2000, 20:9145-51.

23. Durbec $\mathrm{P}, \mathrm{Cremer} \mathrm{H}$ : Revisiting the function of PSA-NCAM in the nervous system. Mol Neurobio/ 2001, 24:53-64

24. Dityatev A, Dityateva G, Sytnyk V, Delling M, Toni N, Nikonenko I, Muller D, Schachner M: Polysialylated neural cell adhesion molecule promotes remodeling and formation of hippocampal synapses. J Neurosci 2004, 24:9372-9382.

25. Morimoto K, Fahnestock M, Racine RJ: Kindling and status epilepticus models of epilepsy: rewiring the brain. Progress in Neurobio 2004, 73:1-60.

26. Mason CR, Cooper RM: A permanent change in convulsive threshold in normal and brain-damaged rats with repeated small doses of pentylenetetrazol. Epilepsia 1972, 13:663-674.

27. Sato K, Iwai M, Nagano I, Shoji M, Abe K: Changes of localization of highly polysialylated neural cell adhesion molecule (PSA-NCAM) in rat hippocampus with exposure to repeated kindled seizures. Brain Res 2002, 946:323-7.

28. Siddiqui $\mathrm{AH}$, Joseph $\mathrm{SA}$ : CA3 axonal sprouting in kainate-induced chronic epilepsy. Brain Res 2005, 1066:129-46.

29. Racine RJ: Modification of seizure activity by electrical stimulation. /I. Motor seizure. Electroencephalogr Clin Neurophysiol 1972, 32:281-94.

30. Giorgi O, Orlandi M, Lecca D, Corda MG: MK-801 prevents chemical kindling induced by pentylenetetrazol in rats. Eur J Pharmacol 1991, 14:363-5.

31. Quartu M, Serra MP, Boi M, Melis T, Ambu R, Del Fiacco M: Brain-derived neurotrophic factor (BDNF) and polysialylated-neural cell adhesion molecule (PSA-NCAM): codistribution in the human brainstem precerebellar nuclei from prenatal to adult age. Brain Research 2010 doi:10.1016/j.brainres.09.106. 
32. Paxinos $\mathrm{G}$, Watson $\mathrm{C}$ : The rat brain in stereotaxic coordinates. 6th edition. Sydney: Academic; 2007.

33. Ebrahimzadeh Bideskan AR, Hassanzadeh Taheri MM, Nikravesh MR, Faze AR: Lectin histochemical study of vasculogenesis during rat pituitary morphogenesis. IJBMS 2011, 14:35-41.

34. Bayer SA: Development of the hippocampal region in the rat II. Morphogenesis during embryonic and early postnatal life. J Compar Neurol 1980, 190:115-134.

35. Hatten ME: Central nervous system neuronal migration. Annu Rev Neurosci 1999, 22:511-539.

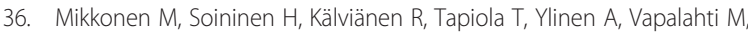
Paljärvi L, Pitkänen A: Remodeling of neuronal circuitries in human temporal lobe epilepsy: increased expression of highly polysialylated neural cell adhesion molecule in the hippocampus and the entorhinal cortex. Ann Neurol 1998, 44:923-34.

37. Mathern GW, Leiphart JL, De Vera A, Adelson PD, Seki T, Neder L, Leite JP: Seizures decrease postnatal neurogenesis and granule cell development in the human fascia dentata. Epilepsia 2002, 43:68-73.

38. Pirttilä TJ, Manninen A, Jutila L, Nissinen J, Kälviäinen R, Vapalahti M, Immonen A, Paljärvi L, Karkola K, Alafuzoff I, Mervaala E, Pitkänen A: Cystatin $C$ expression is associated with granule cell dispersion in epilepsy. Ann Neurol 2005, 58:211-23.

39. Matsuyama T, Tsuchiyama M, Nakamura H, Matsumoto M, Sugita M: Hilar somatostatin neurons are more vulnerable to an ischemic insult than CA1 pyramidal neurons. J Cereb Blood Flow Metab 1993, 13:229-34.

40. Miki T, Harris SJ, Wilce P, Takeuchi Y, Bedi KS: Neurons in the hilus region of the rat hippocampus are depleted in number by exposure to alcohol during early postnatal life. Hippocampus 2000, 10:284-95.

41. Rajabzadeh AA: Ebrahimzadeh Bideskan AR, Haghir H, Fazel AR: Morphometrical study of PSA-NCAM positive cells in rat pups hippocampus following induction of seizure during pregnancy. Iran Biomed J 2011, 15:157-163. doi:10.6091/IBJ.998.2012.

42. Parent JM, Elliott RC, Pleasure SJ, Barbaro NM, Lowenstein DH: Aberrant seizure-induced neurogenesis in experimental temporal lobe epilepsy. Ann Neurol 2006, 59:81-91.

43. Saegusa T, Mine S, Iwasa H, Murai H, Seki T, Yamaura A, Yuasa S: Involvement of highly polysialylated neural cell adhesion molecule (PSA-NCAM)-positive granule cells in the amygdaloid-kindling-induced sprouting of a hippocampal mossy fiber trajectory. Neurosci Res 2004, 48:185-194.

44. Parent JM, Valentin $\mathrm{W}$, Lowenstein $\mathrm{DH}$ : Prolonged seizures increase proliferating neuroblasts in the adult rat subventricularzone-olfactory bulb pathway. I Neurosci 2002, 22:3174-3188.

45. Parent JM, Tada E, Fike JR, Lowenstein $\mathrm{DH}$ : Inhibition of dentate granule cell neurogenesis with brain irradiation does not prevent seizureinduced mossy fiber synaptic reorganization in the rat. J Neurosci 1999, 19:4508-4519.

46. McCabe BK, Silveira DC, Cilio MR, Cha BH, Liu X, Sogawa Y, Holmes GL: Reduced neurogenesis after neonatal seizures. J Neurosci 2001, 21:2094-103.

47. Gascon E, Vutskits L, Jenny B, Durbec P, Kiss JZ: PSA-NCAM in postnatally generated immature neurons of the olfactory bulb: a crucial role in regulating p75 expression and cell survival. Development 2007, 134:1181-1190. doi:10.1242/dev.02808.

48. Borght K, Brundin P: Reduced expression of PSA-NCAM in the hippocampus and piriform cortex of the R6/1 and R6/2 mouse models of Huntington's disease. Exp Neurol 2007, 204:473-478.

49. Muller D, Wang C, Skibo G, Toni N, Cremer H, Calaora V, Rougon G, Kiss JZ: PSA-NCAM is required for activity-induced synaptic plasticity. Neuron 1996, 17:413-422.

50. Seki T, Arai Y: Highly polysialylated neural cell adhesion molecule (NCAM-H) is expressed by newly generated granule cells in the dentate gyrus of the adult rat. J Neurosci 1993, 13:2351-2358.

51. Iwai M, Hayashi T, Zhang WR, Sato K, Manabe Y, Abe K: Induction of highly polysialylated neural cell adhesion molecule (PSA-NCAM) in postischemic gerbil hippocampus mainly dissociated with neural stem cell proliferation. Brain Res 2001, 902:288-93.

52. Golan H, Kashtuzki I, Hallak M, Sorokin Y, Huleihel M: Maternal hypoxia during pregnancy induces fetal neurodevelopmental brain damage: partial protection by magnesium sulfate. J Neurosci Res 2004, 78:430-41.
53. Foley AG, Murphy KJ, Regan CM: Complex-environment rearing prevents prenatal hypoxia-induced deficits in hippocampal cellular mechanisms necessary for memory consolidation in the adult Wistar Rat. J Neurosci Res 2005, 82:245-254.

54. Romanko MJ, Rothstein RP, Levison SW: Neural stem cells in the subventricularzone are resilient to hypoxia/ischemia whereas progenitors are vulnerable. J Cereb Blood Flow \& Metabol 2004 doi:10.1097/01.WCB.0000123906.17746.00.

55. Holopainen IE: Seizures in the developing brain: Cellular and molecular mechanisms of neuronal damage, neurogenesis and cellular reorganization. Neurochem Internat 2008, 52:935-947.

56. Rodriguez JJ, Montaron MF, Petry KG, Aurousseau C, Marinelli M, Premier S, Rougon $G$, LeMoal M, Abrous DN: Complex regulation of the expression of the polysialylated form of the neuronal cell adhesion molecule by glucocorticoids in the rat hippocampus. Europ J Neurosci 1998, 10:2994-3006

57. Nacher J, Gomez-Climent MA, Ewenb BM: Chronic non-invasive glucocorticoid administration decreases polysialylated neural cell adhesion molecule expression in the adult rat dentate gyrus. Neurosci Lett 2004, 370:40-44.

doi:10.1186/1423-0127-19-56

Cite this article as: Rajabzadeh et al:: The effect of PTZ-induced epileptic seizures on hippocampal expression of PSA-NCAM in offspring born to kindled rats. Journal of Biomedical Science 2012 19:56.

\section{Submit your next manuscript to BioMed Central and take full advantage of:}

- Convenient online submission

- Thorough peer review

- No space constraints or color figure charges

- Immediate publication on acceptance

- Inclusion in PubMed, CAS, Scopus and Google Scholar

- Research which is freely available for redistribution 